Izaak J. de Hulster

\title{
Iconographic Exegesis and Third Isaiah
}

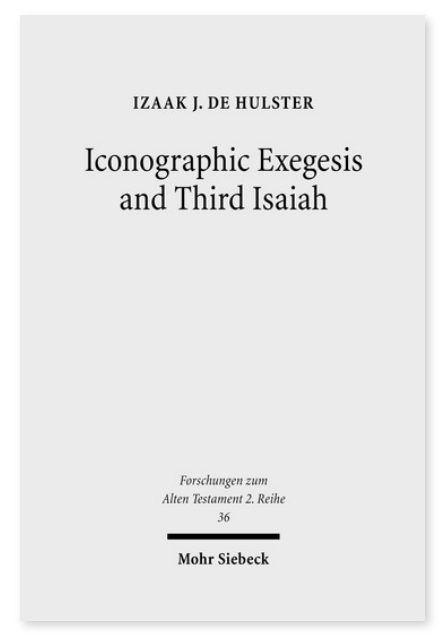

2009. XV, 353 Seiten. FAT II 36

ISBN 978-3-16-151134-9

DOI 10.1628/978-3-16-151134-9

eBook PDF 89,00€

ISBN 978-3-16-150029-9

fadengeheftete Broschur $89,00 €$ [lkonographische Exegese und Tritojesaja.]

Veröffentlicht auf Englisch.

Izaak J. de Hulster entwirft eine Methode zur Verwendung des Bildmaterials des Alten Orients in der (alttestamentlichen) Exegese. Dabei berücksichtigt er so bedeutende theoretische Fragen wie 'Was ist ein Bild?' und 'Was ist Kultur?' und unternimmt ein interdisziplinäre Untersuchung von geschichtlichen, kunstgeschichtlichen, archäologischen und kulturanthropologischen Themen. De Hulster schlägt eine Vorgehensweise in drei Schritten vor, die in hermeneutische und exegetische Reflexionen eingebettet ist und bezieht die ikonographische Exegese auf die Interpretation von Metaphern. Anschließend wendet de Hulster seine Methode anhand von drei Fallstudien auf die Themen bildloses Denkmal (Jesaja 56,5), Licht (Jesaja 60) und das Keltern von Trauben (Jesaja 63) an.

Izaak J. de Hulster Born 1979; 2008 PhD (Utrecht); since 2014 University Researcher at the Faculty of Theology, University of Helsinki; 2017 Habilitation (Göttingen).

https://orcid.org/0000-0003-0706-4480
Jetzt bestellen:

https://mohrsiebeck.com/buch/iconographic-exegesis-and-third-isaiah-9783161511349?no_cache=1

order@mohrsiebeck.com

Telefon: +49 (0)7071-923-17

Telefax: +49 (0)7071-51104 